\title{
Detection of New Methicillin-Resistant Staphylococcus aureus Clones Containing the Toxic Shock Syndrome Toxin 1 Gene Responsible for Hospital- and Community-Acquired Infections in France
}

\author{
Geraldine Durand, ${ }^{1}$ Michèle Bes,${ }^{1}$ Helene Meugnier, ${ }^{1}$ Mark C. Enright, ${ }^{2}$ Françoise Forey, ${ }^{1}$ \\ Nadia Liassine, ${ }^{3}$ Aline Wenger, ${ }^{4}$ Ken Kikuchi, ${ }^{5}$ Gerard Lina, ${ }^{1}$ \\ François Vandenesch, ${ }^{1}$ and Jerome Etienne ${ }^{1 *}$
}

\begin{abstract}
Centre National de Référence des Staphylocoques, Faculté Laennec, INSERM E0230, IFR62, 7 Rue Guillaume Paradin, 69372 Lyon Cedex 08, France ${ }^{1}$; Department of Biology and Biochemistry, University of Bath, Bath, United Kingdom BA2 7AY ${ }^{2}$, Bioanalytique-Riotton, Unilabs, 1211 Geneva 2, Switzerland ${ }^{3}$; Laboratoire Bactériologie Médicale,

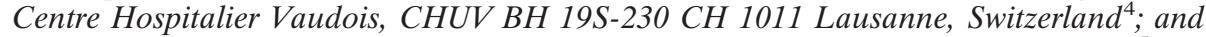
Department of Infectious Diseases, Tokyo Women's Medical University, Tokyo, Japan ${ }^{5}$
\end{abstract}

Received 1 September 2005/Returned for modification 21 November 2005/Accepted 28 December 2005

\begin{abstract}
Methicillin-resistant Staphylococcus aureus (MRSA) clones harboring the toxic shock syndrome toxin 1 ( $t$ st) gene have been detected in France and in Switzerland since 2002. During a passive survey conducted between 2002 and 2003, we collected 103 tst-positive $S$. aureus isolates from 42 towns in France, of which 27 were resistant to methicillin. The tst-positive MRSA belonged to two clones: a major clone comprising 25 isolates of sequence type (ST) 5 and $a g r$ group 2 and a minor clone comprising two isolates of ST30 and agr3. The tst-positive MRSA clones were associated with both hospital-acquired (12 cases) and community-acquired (8 cases) infections. The MRSA clones were mainly isolated from children (overall median age, 3 years). They caused a variety of clinical syndromes, including toxic shock syndrome and suppurative infections. Both clones were found to harbor a type IV staphylococcal chromosomal cassette mec (SCCmec) and to have similar antibiotic resistance profiles (usually resistant to oxacillin, kanamycin, and tobramycin and with intermediate resistance to fusidic acid). The origin of these clones is unclear. The tst-positive agr 2 MRSA clone has the same sequence type (ST5) of two pandemic nosocomial MRSA clones, namely, the Pediatric clone and the New York/Japan clone. These findings suggest that all these clones are phylogenetically related. The pulsotype of the tst-positive MRSA clones differed from that of methicillin-sensitive $S$. aureus (MSSA) clones by a single band involving the SCCmec element. These findings suggest that the tst-positive MRSA clones may have emerged from their respective MSSA counterparts.
\end{abstract}

Staphylococcus aureus is an important human pathogen in both hospitals and the community. The first methicillin-resistant $S$. aureus (MRSA) isolates were detected in the hospital setting in the early 1960s. A number of pandemic nosocomial clones have been characterized by molecular methods (3, 24, 25, 34). These epidemic MRSA strains of hospital origin have also been detected in the community, infecting patients with risk factors associated with hospital-acquired MRSA infection (H-MRSA), such as recent hospitalization. The epidemiology of MRSA has changed radically since 1999; in particular, true community-acquired MRSA (C-MRSA) infections have been reported in patients with no clear risk factors (2). These CMRSA clones predominantly infect young and previously healthy patients and have now spread throughout the world (29). They produce Panton-Valentine leucocidin (PVL) and harbor a type IV staphylococcal chromosomal cassette mec (SCCmec) element $(1,4,5,13,22,37)$.

Toxic shock syndrome toxin 1 (TSST-1) is a superantigenic toxin secreted by some $S$. aureus isolates. TSST-1, encoded by the $t s t$ gene, is a major virulence factor in toxic shock syndrome

\footnotetext{
* Corresponding author. Mailing address: Centre National de Référence des Staphylocoques, Faculté Laennec, INSERM E0230, IFR62, 7 Rue Guillaume Paradin, 69372 Lyon cedex 08, France. Phone: 33478 7786 57. Fax: 334787786 58. E-mail: jetienne@univ-lyon1.fr.
}

(TSS), staphylococcal scarlet fever, and neonatal toxic shocklike exanthematous diseases (NTED) recently described in Japan and France $(11,16,38)$. TSS was first described in 1978 by Todd et al. as a multisystem disease characterized by rapid onset of fever, hypotension, erythematous rash, and mucosal hyperemia, followed by desquamation and multiorgan involvement. TSS was initially linked to tampon use by young women, but non-menstruation-associated TSS now predominates, occurring both in the community and in hospitals secondary to local S. aureus infection (10). Musser et al. showed that tstpositive $S$. aureus strains were clonal by comparing their isoenzymatic profiles (21), and studies based on multilocus sequence typing (MLST) have recently shown that these strains belong to sequence type (ST) 30 (27). Jarraud et al. reported that most tstpositive $S$. aureus strains are genetically related and have a type 3 accessory gene regulator (agr) allele (15). The isolates in these studies were associated with community- and hospitalacquired diseases and were all methicillin-sensitive $S$. aureus (MSSA). There have been few reports of MRSA isolates producing TSST-1 in Japan or Germany (12, 30). In 2003, we observed the first French case of NTED due to TSST-1-producing methicillin-resistant $S$. aureus $(16,38)$.

In order to characterize TSST-1-producing $S$. aureus isolates in France, we retrospectively typed all $t s t$-positive isolates sent to the French National Reference Center for Staphylococci in 
2002 and 2003 and collected relevant epidemiological and clinical data. We observed the presence of new tst-positive MRSA clones responsible for both hospital- and community-acquired infections.

\section{MATERIALS AND METHODS}

Bacterial isolates. Among the 1,550 unconstrained strains sent to the French National Reference Center for Staphylococci during 2002 and 2003, 103 isolates from 42 towns were tst positive. As controls we used nine tst-positive MRSA isolates from Australia (one isolate, provided by Graeme Nimmo), Switzerland (three isolates), and Japan (five isolates causing neonatal toxic shock-like exanthematous diseases, TWCC3812, TWCC390861, TWCC4082, TWCC4382, and TWCC4410) (16). We also used an isolate representative of the Pediatric clone and an isolate representative of the New York/Japan clone.

Data collection. For each $S$. aureus strain we collected relevant clinical information (age, sex, type, and site of infection) by using a standard form provided by the French National Reference Center for Staphylococci. TSS, staphylococcal scarlet fever, and neonatal toxic shock syndrome-like NTED were diagnosed by using published criteria $(11,21,30,32)$. For this study, MRSA infection was considered to be community acquired if the specimen was obtained outside the hospital setting or less than 2 days after hospital admission of a patient with no direct or indirect exposure to the healthcare system in the previous year (2).

DNA extraction. Strains were grown on brain heart infusion agar or in brain heart infusion broth at $37^{\circ} \mathrm{C}$ overnight. Genomic DNA was extracted with a standard procedure, and its concentration was estimated spectrophotometrically (18). Amplification of gyrA was used to confirm the quality of each DNA extract and the absence of PCR inhibitors. All PCR products were analyzed by electrophoresis on ethidium bromide-stained 1\% agarose gels (Sigma, France).

Identification of $a g r$ alleles. The $\operatorname{agr}$ group $(\operatorname{agr} 1$ to -4$)$ was determined by PCR as previously described (15).

Detection of the mecA gene and SCCmec typing. The mecA gene coding for methicillin resistance was detected by PCR as described by Murakami et al. (20). The staphylococcal chromosomal cassette mec (SCCmec I to IV) was detected by using the method of Oliveira et al. (23). The following reference strains, kindly provided by Herminia de Lencastre and Alexander Tomasz, were used as controls: COL (SCCmec I), BK2464 (SCCmec II), HU106 (SCCmec III), and BK2529 (SCCmec IV).

Detection of toxin and adhesin genes. Sequences specific for staphylococcal enterotoxin genes (sea-e and seg-o), the toxic shock syndrome toxin gene (tst), exfoliative toxin genes ( $e t a$ and $e t b)$, PVL genes (lukS-PV-lukF-PV), the LukElukD leukocidin genes (lukE-lukD), the class F lukM leukocidin gene (lukM), and hemolysin genes (gamma $[h l g]$, gamma variant $[h l g v]$, and beta $[h l b]$ ) and for nine MSCRAMM genes (microbial surface components recognizing adhesive matrix molecules), bone sialoprotein binding protein ( $b s p)$, clumping factors $\mathrm{A}$ and $\mathrm{B}$ (clfA and -B), collagen binding protein (cna), elastin binding protein (ebpS), laminin binding protein (eno), fibronectin binding proteins $\mathrm{A}$ and $\mathrm{B}$ ( $f n b A$ and $-B)$, and extracellular fibrinogen binding protein $(e f b)$, were detected by PCR as described elsewhere $(15,23,26,27,35,37)$.

Antimicrobial susceptibility testing. Susceptibility tests were performed with the ATB System (bioMérieux, France).

Capsular typing. Capsular serotyping was performed for all MRSA strains and for randomly selected MSSA strains. The strains were grown for $24 \mathrm{~h}$ at $37^{\circ} \mathrm{C}$ on Columbia agar plates containing $2 \% \mathrm{MgCl}_{2}$ and $0.5 \% \mathrm{CaCl}_{2}$. Several colonies of each strain were suspended in $0.9 \%$ saline and tested by slide agglutination with rabbit polyclonal antibodies specific for capsular polysaccharide types 5 and $8(8,9)$.

Fingerprinting by PFGE. SmaI macrorestriction patterns were obtained by using a contour-clamped homogeneous electric field DR-II apparatus (Bio-Rad), as described elsewhere (19). Strain NCTC 8325 was used as a pulsed-field gel electrophoresis (PFGE) control. Resolved macrorestriction patterns were compared as recommended by Tenover et al. (33). Isolates were assigned to a single clonal group if they differed by less than six bands. PFGE patterns with more than six band differences ( $<75 \%$ similarity) were considered to correspond to different types.

The mecA gene was tested for in one of the PFGE bands, as follows: the fragment was cut out from the agarose gel, DNA was extracted by using the MinElute gel extraction kit protocol (QIAGEN), and PCR with the mecA primers and multiplex PCR for SCCmec typing were performed on the extract as described above.

spa typing. spa typing was performed on MRSA isolates and on agr2 MSSA isolates, as previously described (14). The $\mathrm{x}$ region of the spa gene was amplified
TABLE 1. Distribution of the mecA gene and agr alleles among 103 French $S$. aureus isolates containing the tst gene collected between 2002 and 2003

\begin{tabular}{cccr}
\hline $\begin{array}{c}\text { agr allele } \\
\text { type }\end{array}$ & \multicolumn{3}{c}{ No. (\%) of isolates } \\
\cline { 2 - 4 } & $\begin{array}{c}\text { mec } A^{+} \\
(n=27)\end{array}$ & $\begin{array}{c}\text { mecA deficient } \\
(n=76)\end{array}$ & Total \\
\hline 1 & $0(0)$ & $1(1)$ & 1 \\
2 & $25(93)$ & $5(7)$ & 30 \\
3 & $2(7)$ & $70(92)$ & 72 \\
4 & $0(0)$ & $0(0)$ & 0 \\
\hline
\end{tabular}

by PCR. spa types were determined with Ridom Staph Type software (Ridom $\mathrm{GmbH}$, Germany), which automatically detects spa repeats and assigns a spa type. MLST. MLST was performed on strains representative of each clonal group, as described elsewhere $(6,36)$. The allelic profile of each strain was obtained by sequencing internal fragments of seven housekeeping genes (arcC, aroE, glpF, gmk, pta, tpi, and yqiL) and entering them on the MLST home page (http: //saureus.mlst.net), where seven numbers depicting the allelic profile were assigned which defined an ST (6). To determine genetic relationships, MLST data were examined with BURST software ( $b$ ased $u$ pon related sequence types; details are available from http://www.mlst.net/BURST/burst.htm). The algorithm places STs that share five out of seven MLST alleles in a common clonal complex (7).

\section{RESULTS}

Distribution of isolates according to methicillin resistance and agr group. Among the 103 tst-positive $S$. aureus isolates, 27 were methicillin resistant $\left(m e c A^{+}\right)$, and 76 were methicillin susceptible ( $m e c A$ deficient) (Table 1). Twenty-five tst-positive MRSA isolates had agr allele type 2, and two had agr allele type 3. Seventy tst-positive MSSA isolates had agr allele type 3, five isolates had agr allele type 2, and one isolate had agr allele type 1 .

Clinical characteristics of $\boldsymbol{t}$ st-positive MRSA infections. The median age of the 27 patients with $t$ st-positive MRSA infections was 3 years (range, $<1$ month to 84 years), and the sex ratio was 1 . Five patients had toxic shock syndrome, two had NTED (31), and one had staphylococcal scarlet fever; nine patients had toxic shock syndrome but did not fulfill all the criteria of a TSST-1-mediated syndrome (i.e., fever and rash without shock) (Table 2). Five skin infections occurred in patients with varicella. Eight patients had deep-seated infections (pneumonia or osteoarthritis), and no clinical information was available for two other patients. Two deaths occurred. The isolates were recovered from skin and soft tissues (14 isolates), blood (7 isolates), the umbilicus ( 2 isolates from cases of NTED), bronchopulmonary secretions (2 isolates), a prosthesis ( 1 isolate), and a ligament ( 1 isolate).

Information on the hospital or community acquisition of the infection was available for 20 MRSA infections and 51 MSSA infections. The origin of MRSA infection was unknown in seven cases. Eight of the 27 patients with tst-positive MRSA isolates had no known link to healthcare facilities and no known risk factors for MRSA acquisition; these cases were considered to be community acquired. Twelve cases were hospital acquired.

Microbiological characteristics of $t$ st-positive MRSA isolates. The 25 tst-positive agr2 MRSA strains all harbored the sec, sed, sel, sem, seo, lukDE, and hlgv toxin genes and the $c l f A-B, e b p S$, eno, and efb adhesin genes (Table 3). These 
TABLE 2. Clinical data on tst-positive MRSA infections

\begin{tabular}{|c|c|c|c|c|c|c|c|c|}
\hline Clinical presentation & $\begin{array}{l}\text { Patient and } \\
\text { isolate no. }{ }^{a}\end{array}$ & $\begin{array}{l}\text { City of } \\
\text { isolation }\end{array}$ & $\begin{array}{l}\text { Age } \\
\text { (yrs) }\end{array}$ & $\mathrm{Sex}^{b}$ & Samples & Site of acquisition & $\begin{array}{l}a g r \\
\text { type }\end{array}$ & $\begin{array}{l}\text { PFGE } \\
\text { type }\end{array}$ \\
\hline \multirow[t]{5}{*}{ True $\mathrm{TSS}^{c}$} & 1, HT20020212 & Lyon & 2 & M & Skin & Community & 2 & A1 \\
\hline & 2, HT20020255 & Bordeaux & 42 & $\mathrm{~F}$ & Blood & Nosocomial & 2 & A1 \\
\hline & 3, HT20020256 & Bordeaux & 0 & $\mathrm{~F}$ & Blood & Nosocomial & 2 & A1 \\
\hline & 4, НT20030603 & Lyon & 25 & $\mathrm{~F}$ & Blood & Nosocomial & 2 & A1 \\
\hline & 5, HT20030159 & Geneva & 0 & $\mathrm{ND}^{e}$ & Skin & Unknown & 2 & A3 \\
\hline \multirow[t]{9}{*}{ Possible $\mathrm{TSS}^{d}$} & 6 , HT20030119 & Marseille & 3 & $\mathrm{~F}$ & Skin & Nosocomial & 2 & A1 \\
\hline & 7, HT20030369 & Lyon & 0 & M & Skin & Unknown & 2 & $\mathrm{D}$ \\
\hline & 8, HT20030416 & Lyon & 9 & $\mathrm{~F}$ & Skin & Community & 2 & A7 \\
\hline & 9, НT20030618 & Lyon & 8 & $\mathrm{~F}$ & Skin & Unknown & 2 & A2 \\
\hline & 10, НТ20030434 & Marseille & 0 & $\mathrm{~F}$ & Blood & Unknown & 2 & A1 \\
\hline & 11, HT20030727 & Lyon & 84 & $\mathrm{M}$ & Skin & Community & 2 & A1 \\
\hline & 12, НT20030769 & Fréjus & 2 & $\mathrm{~F}$ & Skin & Unknown & 2 & A3 \\
\hline & 13, НT20030695 & Lausanne & 2 & ND & Skin & Unknown & 2 & A10 \\
\hline & 14, НТ20030849 & Geneva & 2 & ND & Skin & Community & 2 & A9 \\
\hline \multirow[t]{5}{*}{ Superinfection of varicella } & 15, НT20020188 & Lyon & 1 & M & Skin & Community & 2 & A1 \\
\hline & 16, НT20020277 & Paris & 1 & M & Skin & Community & 2 & $\mathrm{~A} 8$ \\
\hline & 17, НT20020369 & Lyon & 7 & M & Skin & Community & 2 & $\mathrm{E}$ \\
\hline & 18, НT20030228 & Lyon & 0 & $\mathrm{M}$ & Skin & Community & 2 & A3 \\
\hline & 19, НT20030651 & Lyon & 4 & M & Skin & Community & 2 & A12 \\
\hline \multirow{2}{*}{ NTED } & 20, НT20020780 & Tours & 0 & ND & Umbilicus & Nosocomial & 2 & A3 \\
\hline & 21, HT20020781 & Tours & 0 & ND & Umbilicus & Nosocomial & 2 & A3 \\
\hline Staphylococcal scarlet fever & 22, HT20030157 & Lille & 0 & M & Skin & Unknown & 2 & A3 \\
\hline \multirow[t]{5}{*}{ Pneumonia } & 23, НT20020132 & Boulogne & 27 & $\mathrm{~F}$ & Skin & Nosocomial & 2 & A5 \\
\hline & 24, НТ20020417 & Annecy & 1 & M & Bronchopulmonary secretion & Unknown & 2 & A12 \\
\hline & 25, HT20030216 & Lyon & 65 & $\mathrm{M}$ & Blood & Nosocomial & 2 & A1 \\
\hline & 26, HT20030639 & Lyon & 31 & M & Blood & Nosocomial & 2 & A7 \\
\hline & 27, HT20020459 & Rouen & 1 & $\mathrm{~F}$ & Bronchopulmonary secretion & Nosocomial & 3 & G2 \\
\hline \multirow[t]{3}{*}{ Osteoarthritis } & 28, HT20030749 & Bondy & 0 & $\mathrm{~F}$ & Blood $\mathrm{P}-\mathrm{s}$ - & Unknown & 2 & A4 \\
\hline & 29, НT20030095 & Lyon & 28 & M & Ligament & Nosocomial & 2 & A3 \\
\hline & 30, НT20020665 & Marseille & 14 & $\mathrm{~F}$ & Prosthesis & Nosocomial & 3 & G3 \\
\hline
\end{tabular}

\footnotetext{
${ }^{a}$ Isolates 5, 13, and 14 from Switzerland were not among the 27 French $t$ st-positive MRSA.

${ }^{b} \mathrm{M}$, male; F, female.

${ }^{c}$ Cases associated with TSS according to the reference criteria.

${ }^{d}$ Cases associated with TSS but that did not fulfill all criteria of TSST-1-mediated syndrome.

${ }^{e} \mathrm{ND}$, no data.
}

isolates were of capsular type 5, except for two isolates which could not be typed with this method. All but one were resistant to penicillin, oxacillin, kanamycin, and tobramycin and had intermediate resistance to fusidic acid; the remaining isolate was susceptible to kanamycin and tobramycin (Table 3). Seven isolates were resistant to other antimicrobial agents such as erythromycin, lincomycin, or tetracycline. All had an SCCmec element type IV, except for one isolate which had an SCCmec element type IVA and two isolates which were nontypeable (possibly new SCCmec variants). PFGE gave more diverse results: all but two of the isolates belonged to PFGE type A (14 subtypes), while the remaining isolates were of types $\mathrm{D}$ and $\mathrm{E}$ (Fig. 1). The main spa type was spa 2 (21 isolates). The other isolates had a related spa type that differed by one (spa 10 and spa 242) or two (spa 568) repeats. These isolates were all of ST5, as determined by MLST. Overall, the 25 tst-positive agr2 MRSA isolates were highly clonally related. This clone was detected in 12 towns in France, and three isolates from Switzerland had similar characteristics. Five Japanese tst-positive agr2 MRSA isolates from patients with NTED were related to this clone (Table 3 ).

Two tst-positive agr3 MRSA isolates were identified. They possessed the sea, sem, seo, hlg, clfA-B, cha, and ebpS genes and were of capsular type 8 . These two isolates were resistant to penicillin, oxacillin, kanamycin, tobramycin, and erythromycin and had intermediate resistance to fusidic acid. One isolate had the SCCmec IV element, whereas the other had the SCCmec IVA element. Their PFGE patterns differed by three bands, and both isolates belonged to PFGE type G (Fig. 1). Their spa types differed by only four repeats (spa 638 and spa 584), and both isolates were ST30, as determined by MLST. These two isolates were considered to be clonally related.

Comparison of the tst-positive agr2 isolates with the New York/Japan clone and the Pediatric clone. The 25 tst-positive agr2 MRSA isolates were ST5 and belonged to capsular type 5, like the New York/Japan and Pediatric clones. The New York/ Japan clone contained the tst toxin gene, contrary to the Pediatric clone. The New York/Japan clone also did not contain the toxin gene (sed), contrary to the 25 tst-positive agr 2 MRSA isolates. The 25 tst-positive agr2 MRSA isolates and the Pediatric clone harbored SCCmec element IV, whereas the New York/Japan clone harbored SCCmec element type II. The 25 tst-positive agr 2 MRSA isolates and the New York/Japan clone were spa type 2, while the Pediatric clone was spa type 311 (diverging by only one repeat).

Comparison of tst-positive MRSA isolates with MSSA isolates. The 25 tst-positive agr $2 \mathrm{MRSA}$ isolates and the 5 tstpositive agr2 MSSA isolates had similar virulence determinants, an identical capsular type (type 5) and sequence type (ST5), and a common PFGE type (A) which differed by a 


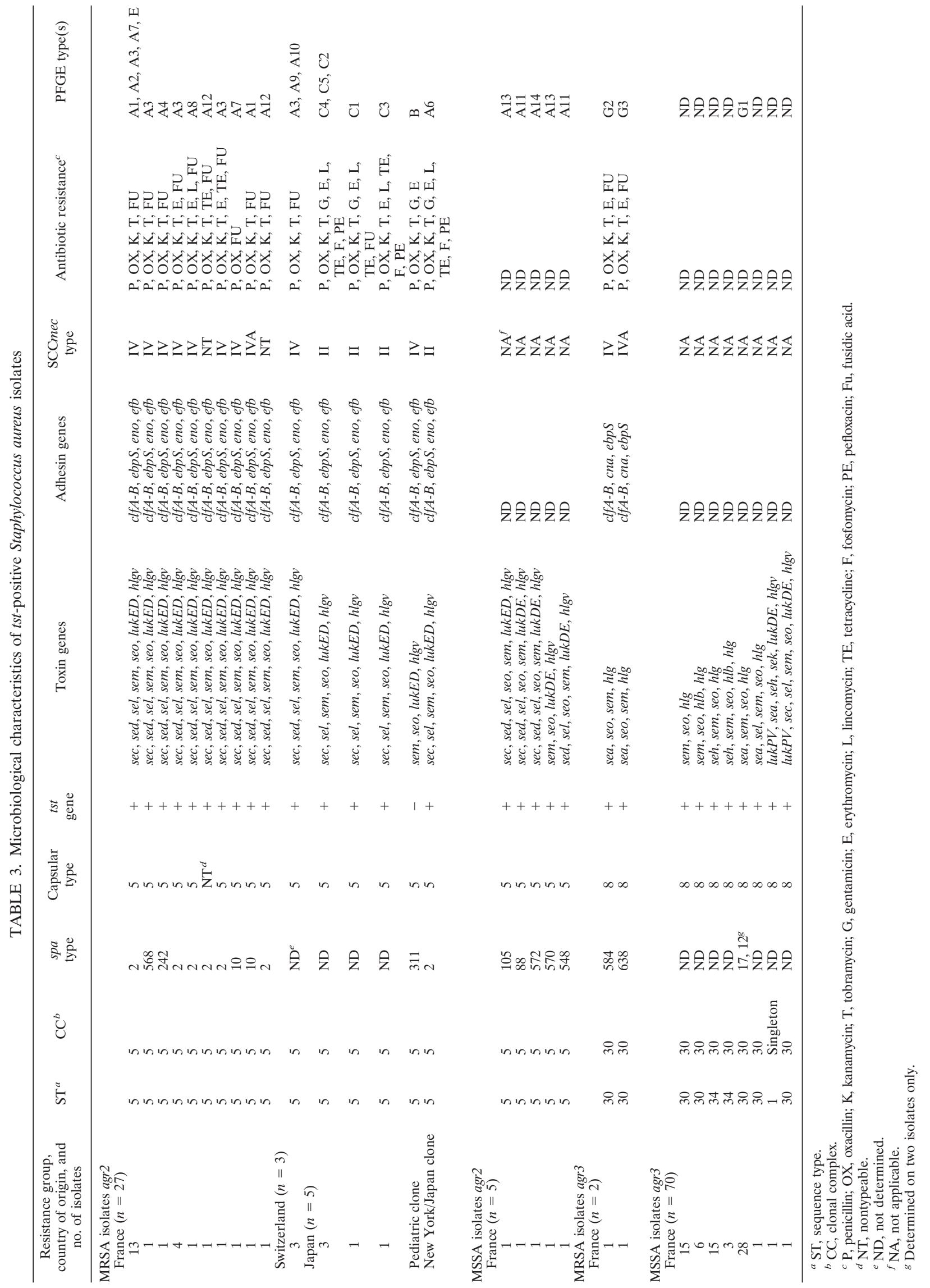




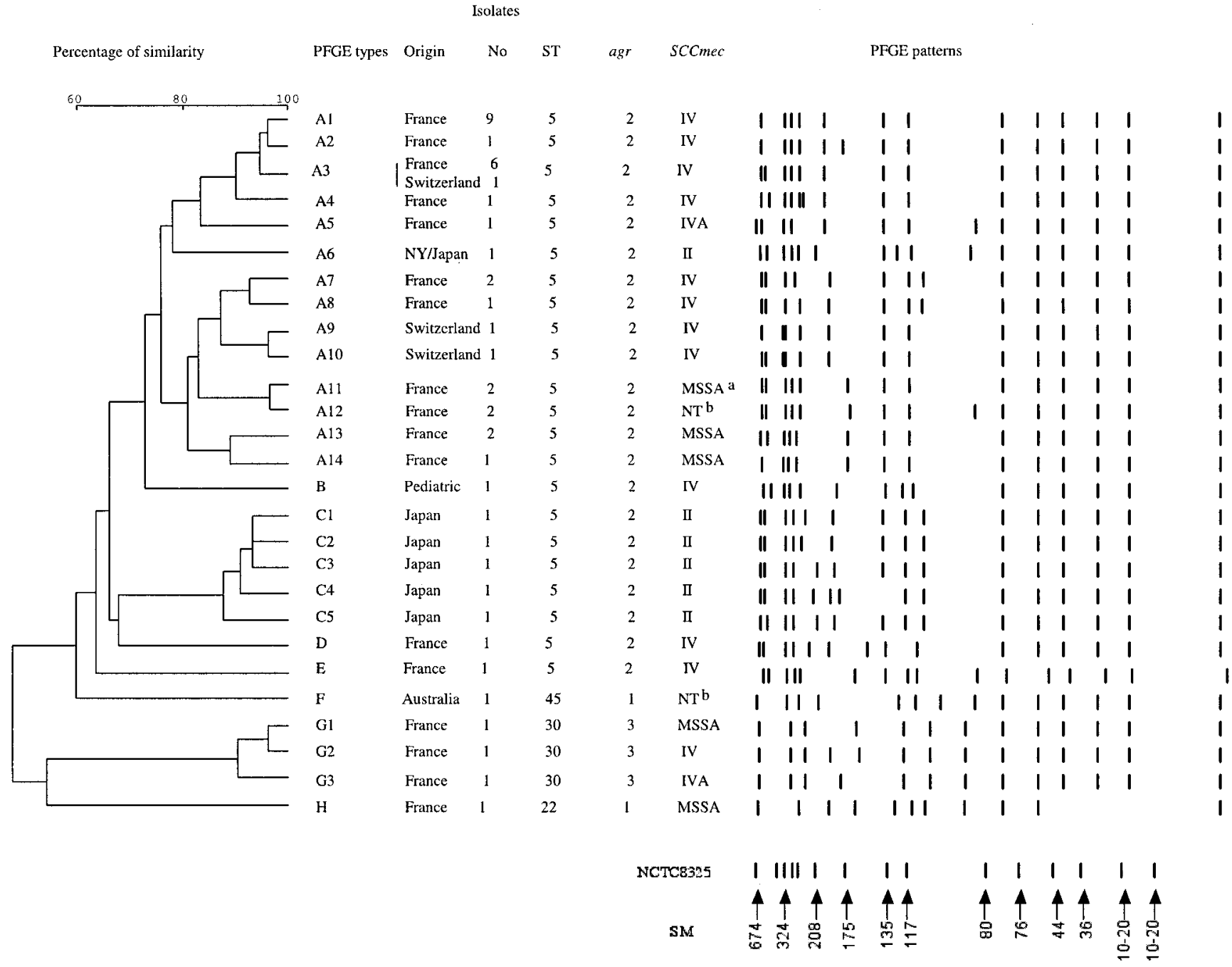

FIG. 1. Unweighted pair group method with averages dendrogram of PFGE results based on the Dice matrix and schematic representation of the pulsotype (SmaI restriction enzyme) of tst-positive MRSA isolates; $S$. aureus NCTC 8325 is the reference strain for the size marker (SM), expressed in kilobases. Isolates differing by more than six fragments were considered to be subtypes of a given clonal type. The agr 2 MRSA clone belonged to the PFGE type A except two isolates of PFGE types D and E. NT ${ }^{\mathrm{b}}$, nontypeable.

single band between the MRSA isolates $(192 \mathrm{~kb})$ and the MSSA isolates $(151 \mathrm{~kb})$. We concluded that the tst-positive agr2 MRSA and MSSA clones were closely related. The presence of the SCCmec IV element in the 192-kb band of MRSA isolates was demonstrated after excising this band from the gel and amplifying mecA and the elements characteristic of SCCmec type IV. mecA and SCCmec PCR were negative for the $151-\mathrm{kb}$ band.

The spa types of the MSSA isolates (spa 88, spa 105, spa 548, spa 570, and spa 572) were very similar to the spa type 2 of the MRSA isolates, diverging by only one or three repeats.

The two tst-positive agr3 MRSA isolates shared characteristics with 25 of the 70 tst-positive agr3 MSSA isolates; their PFGE patterns differed by a single band containing mec $A$ in MRSA isolates. The spa types of two tst-positive agr3 MSSA isolates (spa 12 and spa 17) were closely related to spa types 638 and 584 of the tst-positive agr3 MRSA strain.

\section{DISCUSSION}

A passive survey of $S$. aureus infections in France during 2002 and 2003 identified tst-positive MRSA clones. We identified a major ST5 agr2 clone which included 25 of the 27 tst-positive MRSA isolates, and a minor ST30 agr3 clone accounted for the remaining two isolates. Both clones mainly caused hospital-acquired infections (12 cases), but the ST5 agr2 clone was also sometimes acquired in the community ( 8 cases). These infections mainly affected children (overall median age, 3 years) and corresponded to both TSS and suppurative infections. The clones were widely disseminated throughout France, as tst-positive MRSA isolates were recovered from 12 French towns between 2002 and 2003. In our database, this clone was also detected in 2000 (one case) and in 2001 (two cases); these three cases were hospital acquired. The ST5 agr2 clone was also detected in Switzerland. 
The two French tst-positive MRSA clones had similar antibiotic resistance profiles: they were usually resistant to oxacillin, kanamycin, and tobramycin and had intermediate resistance to fusidic acid, while resistance to erythromycin was more variable. This antibiotic resistance profile is uncommon among French hospital MRSA isolates. Intermediate fusidic acid resistance is rare in French hospital MRSA clones, which are usually susceptible to fusidic acid and resistant to quinolones (39). It is noteworthy that the antibiotic resistance profiles of the two French tst-positive MRSA clones are very similar to that of the major community-acquired ST80 MRSA clone harboring the PVL genes, which is currently spreading throughout Europe (37). For instance, the ST80 clone is also resistant to oxacillin and kanamycin and has intermediate resistance to fusidic acid, whereas it is susceptible to tobramycin and resistant to tetracycline. These differences in antibiotic resistance profiles may help to identify the PVL-positive clone ST80 and the tst-positive clones ST5 and ST30 in the clinical setting. It is surprising that these emerging clones, which are either tst or PVL positive, share certain genetic determinants encoding resistance to antibiotics despite their very different genetic backgrounds. This may reflect a peculiar pattern of antibiotic usage in France, notably in the community.

Two categories of MRSA had previously been recognized in France. The first comprises hospital strains (H-MRSA) that can potentially spread into the community, giving rise to infections in patients with risk factors such as recent hospitalization or surgery, chronic underlying diseases, immunosuppression, or intravenous drug use. The second category corresponds to MRSA strains arising de novo in the community (C-MRSA), which infect patients with no established risk factors. H-MRSA infections differ from C-MRSA infections in their epidemiological, clinical, and microbiological characteristics: C-MRSA infects younger subjects and mainly causes skin infections, whereas H-MRSA is associated with a wider range of infections (urinary tract, respiratory tract, skin, etc.). C-MRSA usually harbors the PVL genes, which are associated with skin and soft tissue infections (37), and occasionally the exfoliative toxin genes (17). The epidemiology of the tst-positive MRSA clones is atypical. Like C-MRSA, tst-positive MRSA generally infects children in the community, but 12 of our cases were strictly hospital acquired. However, it is not known whether the patients with "hospital-acquired" infections were nasal carriers of tst-positive MRSA or whether they actually acquired the strain in the hospital. None of the hospital-acquired tst-positive MRSA infections was associated with hospital outbreaks or with documented horizontal transmission. The known prevalence of H-MRSA in French pediatric units is low (9.8\% in our hospital in Lyon [J. Etienne, personal communication]), as is the overall prevalence of tst-positive MRSA in France (27 isolates from 12 different hospitals in a 2-year period). This suggests that these tst-positive MRSA strains are being imported into hospitals from the community. tst-positive MRSA strains appear to be highly virulent and to cause a variety of illnesses, ranging from toxic shock syndrome to various suppurative infections.

The two tst-positive MRSA clones, with agr2 or agr3 genetic backgrounds, seem to be clonally related to their respective agr 2 or agr3 tst-positive MSSA counterparts. A single PFGE band difference, corresponding to an SCCmec IV element, distinguished the MRSA isolates from the MSSA isolates. It is unclear whether insertion of a mec $A$ element can occur in such MSSA strains. The tst-positive agr2 MSSA clone has rarely been detected in France (only 5 isolates in our collection), contrary to the tst-positive agr3 MSSA clone (70 isolates in our collection). It is surprising that the major tst-positive MRSA clone (agr2) should have emerged from an infrequently detected $t s t$-positive MSSA background. We compared our tstpositive agr 2 MRSA clone with the well-described New York/ Japan and Pediatric MRSA clones that have spread worldwide. Our tst-positive agr $2 \mathrm{MRSA}$ clone has the same genetic background as the New York/Japan clone. Even if SCCmec acquisition by MSSA clones was four times more common than the replacement of one SCCmec by another, we cannot exclude the possibility that our clone arose from the New York/Japan clone through SCCmec II substitution by SCCmec IV (28). Further phylogenetic studies are needed to determine the precise origin of our clone, and these studies may help to identify factors that tend to promote the spread of tst-positive agr2 MRSA rather than $t$ st-positive agr3 MRSA.

Most emerging C-MRSA isolates with heightened virulence have been found to harbor the PVL genes and, less frequently, exfoliative toxin genes (17). The emergence and spread of virulent C-MRSA isolates harboring the tst gene is of major concern, as they appear to share certain characteristics with PVL-positive C-MRSA, including a predilection for children. Prospective studies are needed to determine the incidence of infections due to these different clones, in order to bolster measures aimed at limiting the spread of C-MRSA.

\section{ACKNOWLEDGMENTS}

We thank the clinicians and microbiologists who sent us clinical data and isolates. We thank Christine Courtier, Christine Gardon, and Céline Spinelli for their technical assistance and David Young for editing the manuscript. We are grateful to Herminia de Lencastre, Alexander Tomasz, Graeme R. Nimmo, and John Perry for provinding MRSA strains. We thank Ali Fattom for the gift of capsular typing reagents.

\section{REFERENCES}

1. Baba, T., F. Takeuchi, M. Kuroda, H. Yuzawa, K. Aoki, A. Oguchi, Y. Nagai, N. Iwama, K. Asano, T. Naimi, H. Kuroda, L. Cui, K. Yamamoto, and K. Hiramatsu. 2002. Genome and virulence determinants of high virulence community-acquired MRSA. Lancet 359:1819-1827.

2. Charlebois, E. D., F. Perdreau-Remington, B. Kreiswirth, D. R. Bangsberg, D. Ciccarone, B. A. Diep, V. L. Ng, K. Chansky, B. Edlin, and H. F. Chambers. 2004. Origins of community strains of methicillin-resistant Staphylococcus aureus. Clin. Infect. Dis. 39:47-54.

3. Crisostomo, M. I., H. Westh, A. Tomasz, M. Chung, D. C. Oliveira, and H. de Lencastre. 2001. The evolution of methicillin resistance in Staphylococcus aureus: similarity of genetic backgrounds in historically early methicillinsusceptible and -resistant isolates and contemporary epidemic clones. Proc. Natl. Acad. Sci. USA 98:9865-9870.

4. Daum, R. S., T. Ito, K. Hiramatsu, F. Hussain, K. Mongkolrattanothai, M. Jamklang, and S. Boyle-Vavra. 2002. A novel methicillin-resistance cassette in community-acquired methicillin-resistant Staphylococcus aureus isolates of diverse genetic backgrounds. J. Infect. Dis. 186:1344-1347.

5. Dufour, P., Y. Gillet, M. Bes, G. Lina, F. Vandenesch, D. Floret, J. Etienne, and H. Richet. 2002. Community-acquired methicillin-resistant Staphylococcus aureus infections in France: emergence of a single clone that produces Panton-Valentine leukocidin. Clin. Infect. Dis. 35:819-824.

6. Enright, M. C., N. P. Day, C. E. Davies, S. J. Peacock, and B. G. Spratt. 2000. Multilocus sequence typing for characterization of methicillin-resistant and methicillin-susceptible clones of Staphylococcus aureus. J. Clin. Microbiol. 38:1008-1015.

7. Enright, M. C., D. A. Robinson, G. Randle, E. J. Feil, H. Grundmann, and B. G. Spratt. 2002. The evolutionary history of methicillin-resistant Staphylococcus aureus (MRSA). Proc. Natl. Acad. Sci. USA 99:7687-7692. 
8. Fattom, A., R. Schneerson, S. C. Szu, W. F. Vann, J. Shiloach, W. W. Karakawa, and J. B. Robbins. 1990. Synthesis and immunologic properties in mice of vaccines composed of Staphylococcus aureus type 5 and type 8 capsular polysaccharides conjugated to Pseudomonas aeruginosa exotoxin A Infect. Immun. 58:2367-2374.

9. Fattom, A., R. Schneerson, D. C. Watson, W. W. Karakawa, D. Fitzgerald, I. Pastan, X. Li, J. Shiloach, D. A. Bryla, and J. B. Robbins. 1993. Laboratory and clinical evaluation of conjugate vaccines composed of Staphylococcus aureus type 5 and type 8 capsular polysaccharides bound to Pseudomonas aeruginosa recombinant exoprotein A. Infect. Immun. 61:1023-1032.

10. Fitzgerald, J. R., D. E. Sturdevant, S. M. Mackie, S. R. Gill, and J. M. Musser. 2001. Evolutionary genomics of Staphylococcus aureus: insights into the origin of methicillin-resistant strains and the toxic shock syndrome epidemic. Proc. Natl. Acad. Sci. USA 98:8821-8826.

11. Floret, D. 2001. Clinical aspects of streptococcal and staphylococcal toxinic diseases. Arch. Pediatr. 8(Suppl. 4):762s-768s.

12. Ghebremedhin, B., W. Konig, and B. Konig. 2005. Heterogeneity of methicillin-resistant Staphylococcus aureus strains at a German university hospital during a 1-year period. Eur. J. Clin. Microbiol. Infect. Dis. 24:388-398.

13. Gillet, Y., B. Issartel, P. Vanhems, J. C. Fournet, G. Lina, M. Bes, F Vandenesch, Y. Piemont, N. Brousse, D. Floret, and J. Etienne. 2002. Association between Staphylococcus aureus strains carrying gene for PantonValentine leukocidin and highly lethal necrotising pneumonia in young immunocompetent patients. Lancet 359:753-759.

14. Harmsen, D., H. Claus, W. Witte, J. Rothganger, D. Turnwald, and U. Vogel. 2003. Typing of methicillin-resistant Staphylococcus aureus in a university hospital setting by using novel software for spa repeat determination and database management. J. Clin. Microbiol. 41:5442-5448.

15. Jarraud, S., C. Mougel, J. Thioulouse, G. Lina, H. Meugnier, F. Forey, X. Nesme, J. Etienne, and F. Vandenesch. 2002. Relationships between Staphylococcus aureus genetic background, virulence factors, agr groups (alleles), and human disease. Infect. Immun. 70:631-641.

16. Kikuchi, K., N. Takahashi, C. Piao, K. Totsuka, H. Nishida, and T. Uchiyama 2003. Molecular epidemiology of methicillin-resistant Staphylococcus aureus strains causing neonatal toxic shock syndrome-like exanthematous disease in neonatal and perinatal wards. J. Clin. Microbiol. 41:3001-3006.

17. Liassine, N., R. Auckenthaler, M. C. Descombes, M. Bes, F. Vandenesch, and J. Etienne. 2004. Community-acquired methicillin-resistant Staphylococcus aureus isolated in Switzerland contains the Panton-Valentine leukocidin or exfoliative toxin genes. J. Clin. Microbiol. 42:825-828.

18. Lina, G., A. Quaglia, M. E. Reverdy, R. Leclercq, F. Vandenesch, and J. Etienne. 1999. Distribution of genes encoding resistance to macrolides, lincosamides, and streptogramins among staphylococci. Antimicrob. Agents Chemother. 43:1062-1066.

19. Maslow, J. N., M. E. Mulligan, and R. D. Arbeit. 1993. Molecular epidemiology: application of contemporary techniques to the typing of microorganisms. Clin. Infect. Dis. 17:153-162.

20. Murakami, K., W. Minamide, K. Wada, E. Nakamura, H. Teraoka, and S. Watanabe. 1991. Identification of methicillin-resistant strains of staphylococci by polymerase chain reaction. J. Clin. Microbiol. 29:2240-2244.

21. Musser, J. M., P. M. Schlievert, A. W. Chow, P. Ewan, B. N. Kreiswirth, V. T Rosdahl, A. S. Naidu, W. Witte, and R. K. Selander. 1990. A single clone of Staphylococcus aureus causes the majority of cases of toxic shock syndrome. Proc. Natl. Acad. Sci. USA 87:225-229.

22. Naimi, T. S., K. H. LeDell, K. Como-Sabetti, S. M. Borchardt, D. J. Boxrud, J. Etienne, S. K. Johnson, F. Vandenesch, S. Fridkin, C. O'Boyle, R. N. Danila, and R. Lynfield. 2003. Comparison of community- and health careassociated methicillin-resistant Staphylococcus aureus infection. JAMA 290: 2976-2984.

23. Oliveira, D. C., and H. de Lencastre. 2002. Multiplex PCR strategy for rapid identification of structural types and variants of the mec element in methi- cillin-resistant Staphylococcus aureus. Antimicrob. Agents Chemother. 46: 2155-2161.

24. Oliveira, D. C., A. Tomasz, and H. de Lencastre. 2001. The evolution of pandemic clones of methicillin-resistant Staphylococcus aureus: identification of two ancestral genetic backgrounds and the associated mec elements. Microb. Drug Resist. 7:349-361.

25. Oliveira, D. C., A. Tomasz, and H. de Lencastre. 2002. Secrets of success of a human pathogen: molecular evolution of pandemic clones of methicillinresistant Staphylococcus aureus. Lancet Infect. Dis. 2:180-189.

26. Peacock, S. J., G. D. de Silva, A. Justice, A. Cowland, C. E. Moore, C. G. Winearls, and N. P. Day. 2002. Comparison of multilocus sequence typing and pulsed-field gel electrophoresis as tools for typing Staphylococcus aureus isolates in a microepidemiological setting. J. Clin. Microbiol. 40:3764-3770.

27. Peacock, S. J., C. E. Moore, A. Justice, M. Kantzanou, L. Story, K. Mackie, G. O'Neill, and N. P. Day. 2002. Virulent combinations of adhesin and toxin genes in natural populations of Staphylococcus aureus. Infect. Immun. 70: 4987-4996.

28. Robinson, D. A., and M. C. Enright. 2003. Evolutionary models of the emergence of methicillin-resistant Staphylococcus aureus. Antimicrob. Agents Chemother. 47:3926-3934.

29. Said-Salim, B., B. Mathema, and B. N. Kreiswirth. 2003. Community-acquired methicillin-resistant Staphylococcus aureus: an emerging pathogen. Infect. Control Hosp. Epidemiol. 24:451-455.

30. Schmitz, F. J., C. R. MacKenzie, R. Geisel, S. Wagner, H. Idel, J. Verhoef, U. Hadding, and H. P. Heinz. 1997. Enterotoxin and toxic shock syndrome toxin-1 production of methicillin resistant and methicillin sensitive Staphylococcus aureus strains. Eur. J. Epidemiol. 13:699-708.

31. Takahashi, N., H. Kato, K. Imanishi, K. Miwa, S. Yamanami, H. Nishida, and T. Uchiyama. 2000. Immunopathophysiological aspects of an emerging neonatal infectious disease induced by a bacterial superantigen. J. Clin. Investig. 106:1409-1415.

32. Takahashi, N., H. Nishida, H. Kato, K. Imanishi, Y. Sakata, and T. Uchiyama. 1998. Exanthematous disease induced by toxic shock syndrome toxin 1 in the early neonatal period. Lancet 351:1614-1619.

33. Tenover, F. C., R. Arbeit, G. Archer, J. Biddle, S. Byrne, R. Goering, G. Hancock, G. A. Hebert, B. Hill, R. Hollis, et al. 1994. Comparison of traditional and molecular methods of typing isolates of Staphylococcus aureus. J. Clin. Microbiol. 32:407-415.

34. Trindade, P. A., J. A. McCulloch, G. A. Oliveira, and E. M. Mamizuka. 2003. Molecular techniques for MRSA typing: current issues and perspectives Braz. J. Infect. Dis. 7:32-43.

35. Tristan, A., L. Ying, M. Bes, J. Etienne, F. Vandenesch, and G. Lina. 2003. Use of multiplex PCR to identify Staphylococcus aureus adhesins involved in human hematogenous infections. J. Clin. Microbiol. 41:4465-4467.

36. Urwin, R., and M. C. Maiden. 2003. Multi-locus sequence typing: a tool for global epidemiology. Trends Microbiol. 11:479-487.

37. Vandenesch, F., T. Naimi, M. C. Enright, G. Lina, G. R. Nimmo, H. Heffernan, N. Liassine, M. Bes, T. Greenland, M. E. Reverdy, and J. Etienne. 2003. Community-acquired methicillin-resistant Staphylococcus aureus carrying PantonValentine leukocidin genes: worldwide emergence. Emerg. Infect. Dis. 9:978984.

38. van der Mee-Marquet, N., G. Lina, R. Quentin, H. Yaouanc-Lapalle, C. Fievre, N. Takahashi, and J. Etienne. 2003. Staphylococcal exanthematous disease in a newborn due to a virulent methicillin-resistant Staphylococcus aureus strain containing the TSST-1 gene in Europe: an alert for neonatologists. J. Clin. Microbiol. 41:4883-4884.

39. van der Mee-Marquet, N., A. S. Domelier, N. Girard, and R. Quentin. 2004. Epidemiology and typing of Staphylococcus aureus strains isolated from bloodstream infections. J. Clin. Microbiol. 42:5650-5657. 